Historical Resources and Creative Education at The Glasgow School of Art Susannah Waters

\title{
Abstract
}

The Glasgow School of Art (GSA, established 1845) has a long history of collecting publications and artefacts to support its teaching of fine art, design and architecture. The School now owns a rich resource of historical material spread across its library, archive and museum collections and overseen by its Learning Resources (LR) department. Can this material continue to support learning and teaching in the creative disciplines in the 21st century? And what are the potential benefits for students? Over the last five years GSA’s LR staff have explored these questions and developed a programme of activities to promote knowledge of this material and understanding of its potential use in fine art, design and architectural education.

\section{The Historical Collections}

GSA's historical collections cover a wide range of material. The library's special collections include publications from the 16th-20th centuries relating to art, design and architecture. The holdings reflect the development of the School's curriculum from its time as a Government School of Design onwards, and are particularly strong in the areas of drawing techniques, 19th-century design, and architectural treatises. A variety of printing techniques and bindings are represented. The School's institutional archive provides a comprehensive record of GSA's activities over the last 167 years through photographic and paper records such as School prospectuses, annual reports, correspondence files, minute books and promotional material. The institutional archive is complemented by archive collections relating to former students and staff which often contain examples of student work and information about the wider creative environment of Glasgow and the West of Scotland. The museum holdings comprise approximately three thousand objects created almost exclusively by GSA alumni. This material ranges from works on paper such as life drawings, architectural designs, and prints, to examples of sculpture, textiles and metalwork. Approximately ten percent of the museum's collections are pieces by Charles Rennie Mackintosh (1868-1928), a GSA alumnus who designed the School's main building (constructed 1897-1899 and 1907-1909) which is 
still in use today. The Mackintosh collection includes architectural drawings and watercolours, as well as furniture designed for GSA and for other Mackintosh commissions. The archive and museum holdings also include a range of material (lantern slides, textiles and plaster casts) which were acquired by the School specifically to support its teaching activities. These items provided students with examples of techniques and styles which they may not have been able to access elsewhere. For example, the lantern slides include images of buildings and costume from around the world; the Needlework Development Scheme textile collection includes examples of embroidery techniques from the 16th-20th centuries; and the plaster cast collection provides three-dimensional, scale copies of classical and medieval sculpture.

\section{Teaching at GSA}

GSA is a small specialist institution providing courses in the areas of fine art, design and architecture, with a student population of approximately 1900. Although some teaching is given in the form of lectures, teaching sessions are often delivered to smaller groups of students through practice-based activities. Undergraduate students are regularly set projects, and are encouraged to present evidence of their preparatory work along with their final pieces. Documenting research methods and the development of ideas and outcomes is therefore a key part of these learning activities with students developing personal and often self-directed approaches to their creative practice. Postgraduate students also work on creative projects, sometimes setting their own briefs and continuing to explore their methodologies and approaches to creative practice. ${ }^{1}$

Referring to visual resources is an important factor in helping all of these creative practitioners develop their ideas and approaches. However, many of GSA's students are not familiar with finding, accessing and using historical resources as part of their visual research. School leavers may be accustomed to accessing library materials and visiting museums but few have had hands-on experience of working directly with historical publications, documents and artefacts. Many undergraduate and postgraduate students may be interested in using historical material but are unsure how to identify and access relevant collections. 
GSA's LR team has identified a number of areas in which working with GSA's historical collections can support the School's teaching activities and students' learning experiences; from developing research, documentation, and analysis skills, to encouraging critical thinking and self-directed learning. From providing a number of one-off historical resources workshops, (created to address specific course or project needs as they arose), LR has consolidated and expanded its activities to now offer a regular programme of events each academic year. Three types of session are described below, working with undergraduate, postgraduate, and widening participation students. All of these sessions link into existing GSA teaching activities, as opposed to being stand-alone events. LR staff believe that this aids attendees' understanding of the relevance of historical material to their creative discipline.

\section{Undergraduate sessions}

The main type of session offered to undergraduate students can be classed as a 'subject specific' induction. In these sessions, students are shown a number of items which relate to their discipline area and / or to a particular project they are working on. Examples of such sessions include: textile pieces, fashion show posters, and photographs being shown to textile students preparing for their third year fashion show; and 16th-18th century architectural treatises being shown to students undertaking an architectural history course on Architecture of the Renaissance. It may seem obvious that textile students will benefit from looking at textiles and architecture students will find architectural treatises of use. However, many of the students that attend these sessions have limited experience of closely viewing original examples of the techniques or historical periods they have been studying. Handling garments (under supervision) allows textile students to consider issues relating to construction, surface decoration, use of colour, scale of pattern, and the weight and texture of materials that cannot be derived by only viewing digital or printed images of such items. The design and production of architectural treatises reveals important information about the development of printing techniques, changing attitudes towards architecture and the status of architects, and the social and economic context in which such publications were produced; information that is not fully revealed by the content of these publications alone.

The undergraduate sessions are usually delivered to about fifteen students with a member of LR staff and a course tutor both present. An hour-long session will usually include ten to 
fifteen items which have been chosen through discussions between the staff involved. Objects are introduced to the students by the LR staff member and students are then encouraged to engage in object analysis by questioning the items for themselves (suggestions of what sort of things they should consider / think about can be provided in a handout). The size of the student group allows for all attendees to see and handle items individually and facilitates group discussion. Having a course tutor present helps to connect these discussions to the course's wider content; course tutors also provide specialist knowledge of their discipline and its techniques. These sessions may seem labour intensive, however, for many course tutors they have become part of an existing programme and so are not additional work. Furthermore, although the LR department's ultimate aim is to enable all students to have the choice of undertaking a course which utilises historical resources at some point during their studies, the relatively small number of students and courses at GSA means that providing a session for each discipline area within the School is not unfeasible. The main obstacle in providing subject specific inductions for all courses is the limitations of our holdings which are stronger in some areas than others (for example, we have very little material relating to interior design and product design). Other approaches to engaging with students from these disciplines have therefore been explored, such as setting design projects which relate to LR's facilities or functions, or providing more general research skills sessions for undergraduate students.

The above sessions aim to provide a stimulus to encourage students to engage more broadly with historical collections (held at GSA or elsewhere) and to provide them with the confidence and ability required to utilise historical material in the future if they so wish. Advice is provided on locating relevant material (using online sources, publications, and personal communication), organising access to these holdings, and on preservation, handling and copyright issues. Such information supports the development of independent research skills, while the structure of the sessions helps students to develop analytical skills and critical thinking through questioning the material in front of them and considering how their own practice relates to other creative contexts as represented by the objects. Students are also asked to think about their own personal responses to the pieces provided in the sessions: What do they or don't they like about the pieces and why? Is there something they find interesting about the history of a piece, its use, or its maker? Students are encouraged to follow their instinctive reactions as a tool in developing creative ideas. 


\section{Postgraduate sessions}

GSA offers a number of taught postgraduate courses. Some of these are primarily studio based and others are more theoretical in nature, however, all taught postgraduate students are required to undertake a research skills course at the beginning of their studies. LR staff have therefore worked with GSA's Postgraduate Co-ordinator to include historical resources as part of this research skills programme. Until this academic year, all taught postgraduate students undertook the same core research skills programme to which LR staff delivered a one hour lecture introducing GSA’s library, archive and museum holdings. Unfortunately, this lecture slot could only provide a very general introduction to the historical collections and did not allow for hands-on access or discussion. However, a restructuring of the research skills programme has resulted in the development of a number of individual courses replacing the original curriculum. These courses focus on specific areas of research with students choosing which one they would like to attend. All of the courses aim to prepare students for graduate level research.

The School's Postgraduate Co-ordinator has developed a 'historical resources' research skills option which comprises nine, two-hour long sessions and covers areas such as the ethics of collecting; preservation and access; the impact of arrangement and taxonomy on the interpretation of collections; and the use of historical resources in contemporary art, design and architecture. LR staff were able to provide input into the content of this course and to deliver two of its sessions: The Book as Object and Archive Activities. These sessions are more theoretical than the subject specific undergraduate inductions described above.

Practical advice on locating, accessing and using historical resources is still included, however, such information sits within a wider philosophical discussion of the use of such material. A broader range of supporting literature and session activities are therefore utilised in order to encourage in-depth thinking and debate. For example, the archive session questioned how archiving activities impact on users’ perceptions of historical material and the histories it represents. This session included a tour of GSA's archive facilities in order to explore the different functions an archive service undertakes, students were then asked to consider their own 'archiving activities' in groups and to feedback to the wider class.

Specific examples from the archives were also examined to see how such activities impact on individual items or collections. Students were assessed for this course by either submitting a 
written or a creative piece of work which related to the course's subject matter. An exhibition of some of the students' work was held earlier this year.

Being involved in this course has broadened LR staff's understanding of how historical resources are viewed by GSA's students and has stimulated the LR team to reconsider their own approaches and understanding of their holdings. A reoccurring theme in class discussions was the view that libraries, archives and museums are often seen as inaccessible institutions which try to control our understanding of culture and history. ${ }^{2}$ These views were generated in part by issues such as the formal access arrangements and defined collecting remits of many institutions that hold historical resources, and were a reminder to LR staff that the promotion of historical material as a rich resource open to the public for individual use and personal interpretation is an ongoing and essential task. Students on this course were also very interested in how to archive their own work. This is something that LR staff have been asked about on a number of occasions and how to include it in future LR sessions is now being considered. Preparing the content for this course has ensured LR staff are up-todate with current professional discourse, it has also encouraged LR staff to gain a greater understanding of approaches to learning and teaching. Three staff members have undertaken CPD study relating to learning and teaching in the creative practices and such study has helped to develop all of the department's activities in this area.

\section{Widening Participation}

GSA has an active widening participation (WP) programme which provides activities for secondary school students who are considering applying to art school. LR staff have recently worked with WP staff to develop sessions in which historical collections help to introduce the students to GSA, by facilitating an understanding of the institution's history, its current approaches to teaching, and the resources available to students. Such activities have included drawing sessions using the GSA's plaster cast collection and creative research days using a variety of material including historical resources. The plaster cast drawing sessions begin by showing attendees examples of drawings created by previous GSA students before they go on to undertake their own work. The original role of the plaster casts as a teaching aid is explained, and the changing role of drawing in GSA's curriculum is discussed. Such information provides attendees with a context for their own drawing, and enables them to feel more at ease working within the art school environment. Drawing from plaster cast figures is 
also a good pre-cursor to attending life drawing classes which can be an intimidating proposition for some. The WP research days use a wider variety of historical resources alongside GSA's contemporary library holdings and computer facilities. Students are given a creative project, perhaps related to a particular subject area or technique, (for example investigating a building or developing textile designs), and are encouraged to use a wide range of resources to build up a portfolio of ideas. A number of primary and secondary sources (including historical and contemporary material) are introduced as a starting point for this research. As with the undergraduate sessions described above, the students are encouraged to analyse and question this material and to consider which of the visual resources or ideas they have read about are of particular interest to them. Their reactions to this material will then shape the direction of their research. Their thoughts and ideas are recorded in a sketchbook which can be submitted as part of their art school application portfolio. This sort of activity introduces the attendees to the project-based teaching environment of the art school, it helps them to develop research and documentation methods, and it provides them with the confidence to use different source material and follow their own instincts. The LR team hope that it will also encourage these individuals to continue to use our resources if they become students at GSA.

\section{Conclusion}

All of the above activities have taken time to embed into the annual teaching activities of GSA and more work is still needed to ensure staff and students are aware of our holdings and how they can support creative practice. LR staff have begun to collect student feedback (using a standard feedback form for all sessions) and continue to seek informal feedback from tutors and students through discussion and email. The feedback LR has received has been extremely positive. Student comments have revealed a real enthusiasm for the historical collections which has affirmed LR staff's own belief in this material's value to the creative disciplines. Some students have requested more information or material is included on particular areas and this feedback will be used in planning future sessions. Discussions with teaching staff have also proved essential in developing and promoting the above programme of activities. Many of these sessions were initiated through staff visiting the LR offices and seeing this material for themselves. It is acknowledged that such a hands-on approach may not be possible for larger institutions but GSA has found a face-to-face, active approach, by 
far the most effective way of engaging with our staff and student communities. The LR department believes that as part of a higher education institution, encouraging the use of its holdings to support teaching and learning is core business. Staff development in the area of learning and teaching has been an important factor in the success of these sessions. LR staff now have a greater understanding of approaches to learning and teaching and are better placed to offer high quality sessions to enhance students experience of studying at the School.

\section{References}

1. More information on the creative practices in higher education can be found in: Alison Shreeve, Shân Wareing and Linda Drew 'Key aspects of teaching and learning in the visual arts’ pp.345-362 in Heather Fry, Steve Kettridge \& Stephanie Marshall (eds) A Handbook for Teaching and Learning in Higher Education Enhancing Academic Practice 3rd edn (London: Routledge, 2009).

2. Similar views were expressed in data gathered by a research project undertaken in 2006 as part of a Centre for Excellence in Teaching and Learning through Design (CETLD) initiative which explored how tutors and students from the Royal College of Art (RCA) and the University of Brighton engaged with museum collections at the Victoria and Albert Museum in order to learn about design. See Catherine Speight 'Museums and Higher Education: A New Specialist Service?' pp.11-28 in 'Beth Cook, Rebecca Reynolds \& Catherine Speight (eds) Museums and Design Education Looking to Learn, Learning to See (Surrey: Ashgate Publishing Ltd, 2010).

Susannah Waters

Archivist

The Glasgow School of Art

167 Renfrew Street

Glasgow

G3 6RQ

$U K$

s.waters@gsa.ac.uk 